\title{
Absenteeism Among Nursing Students: A Case Study at University of Maiduguri, Borno State, Nigeria
}

\author{
Emmanuel Okechukwu Chukwu ${ }^{1,}$, Nafisa Haruna Yakubu ${ }^{2}$, Habu Haruna ${ }^{2}$, Dathini Hamina ${ }^{2}$, \\ Terkuma Chia ${ }^{3}$, Terna Mesuur Fiase ${ }^{1}$, Esther Iornengen ${ }^{4}$ \\ ${ }^{1}$ School of Nursing Mkar, Gboko, Nigeria \\ ${ }^{2}$ Department of Nursing Science, College of Medical Science, University of Maiduguri, Maiduguri, Nigeria \\ ${ }^{3}$ Department of Human Anatomy, College of Medical science, University of Nigeria, Enugu Campus, Enugu, Nigeria \\ ${ }^{4}$ School of Midwifery Mkar, Gboko, Nigeria
}

Email address:

emmanwaguy42@yahoo.com (E. O. Chukwu)

${ }^{*}$ Corresponding author

\section{To cite this article:}

Emmanuel Okechukwu Chukwu, Nafisa Haruna Yakubu, Habu Haruna, Dathini Hamina, Terkuma Chia, Terna Mesuur Fiase, Esther Iornengen. Absenteeism Among Nursing Students: A Case Study at University of Maiduguri, Borno State, Nigeria. American Journal of Library and Information Science. Vol. 3, No. 4, 2017, pp. 46-51. doi: 10.11648/j.ijmfs.20170304.12

Received: April 25, 2017; Accepted: May 11, 2017; Published: July 10, 2017

\begin{abstract}
Absenteeism from clinical areas and lectures among nursing students is a significant problem that if not addressed will adversely affect the quality of nursing care. This cross-sectional descriptive survey design was to assess factors influencing absenteeism among nursing students in University of Maiduguri. A total of 270 respondents were selected using convenient sampling technique after stratified sampling technique was used to ensure that all levels (class) of the nursing students were represented. Data were collected through the use of self- constructed questionnaire which was administered by the researchers and trained assistants. Collected data were presented in frequency and percentage. Mean scores were used to analyze the data. 2.50 was chosen as the bench mark ( $\geq 2.5$ as criteria of acceptance). Inferential statistics (chi-square) [x2] was used to test the hypothesis at 0.05 level of significance. The study findings revealed that majority of students do absent themselves from lectures and clinical postings. Ill-health, nursing a baby, participation in other roles besides academic activities and transportation difficulties are important contributions to absenteeism. Poor grades and carry-over are effects of absenteeism. The researchers recommends among other things that; clinical supervision and attendance list should be taken serious during lectures and clinical posting. The school management board should provide free transportation to clinical areas and accommodations should also be provided for students within campus. Lecture halls and theaters should be made as conducive as possible.
\end{abstract}

Keywords: Absenteeism, Nursing, Students, University, Maiduguri

\section{Introduction}

Absenteeism appears to be a major problem confronting the school system in Nigeria. Absenteeism is not only an epidemic peculiar to the universities, but to all public and private schools in the developed and developing countries. A central assumption in the learning process is that an individual student's presence in an educational environment is a prerequisite for the student to gain from that environment [1]. The magnitude of the problem can be appreciated when one consider the issues and concern raised by individuals and groups in many public gatherings and information media [2]. [3] examined absenteeism trends among 110 third year nursing students in Ireland and discovered that voluntary absence was a major feature of this group and occurred more frequently for lectures than the clinical environment. This authors maintained that a total of 1567 days were lost through absenteeism over 123 weeks, although the most frequency recorded absence from both wards and lectures were mostly of short duration. [4] find that chronic absenteeism affects up to 15 percent of the national student population, or 5 million to 7.5 million students each year; 
with students of color and students living in poverty being most disproportionately affected.

Studies have shown that the reasons proffered by students as explanations for non-attendance to lectures include family, social and work commitment, illness, faking illness, and family emergencies [2]; [5]; [6]. Nurses absenteeism from lectures and clinical practices post a great concern to the society since some aspect of nurses curriculum effects public safety and can result in inadequate learning on the part of those learning especially in the aspect of drug calculations and administrations which could result in drug over dose and poisoning [7]; [8]; [9]. Students showed a high degree of poor academic performance and lower achievement due to absenteeism. It make students stay longer in school and parents are stressed financially. [10] finds that the number of school days present significantly affects multiple measures of achievement and indicates that attendance is a robust predictor of student academic achievement. [11] reported that most school drop out move to a life of misdemeanor, which has a negative impact on the society. If academic standard is not maintained, increased absenteeism will adversely affect the quality of nursing care (health care delivery) and contribute to increase morbidity and mortality rate in the society.

\section{Objectives of the Study}

1) Determine the prevalence of absenteeism among nursing students.

2) Identify factors influencing absenteeism among the students.

3) Determine the effects of absenteeism on the student's performance.

\section{Study Hypotheses}

1) Nursing students do not miss their lectures.

2) There are no factors influencing absenteeism among the nursing students.

3) There are no effects of absenteeism on the students' academic performance.

\section{Methodology}

\subsection{Study Design}

This study is a cross-sectional descriptive survey used to assess absenteeism among nursing students of University of Maiduguri, Borno State.

\subsection{Setting for the Study}

The setting of this study was the Department of Nursing Science, College of Medial Sciences, University of Maiduguri Borno State. The University is one of the federal universities in the North-Eastern region of Nigeria. It is located in Maiduguri, the capital city of Borno State. The department of nursing has preclinical students which comprised of 100 to 200 level and clinical students which comprised of 300 to 500 level students who usually go for clinical posting in the University of Maiduguri Teaching Hospital with other Government Peripheral Hospitals for speciality posting.

\subsection{Sampling Technique and Sample Size}

Following stratified random sampling technique which ensured that all the class of the nursing students were represented in the study, simple random sampling technique was used to select 50 nursing students each from year two to year five and 70 students from year one due to their larger number in class. A total of 270 students constituted the sample size for this study.

\subsection{Instrument for Data Collection}

A self-constructed questionnaire was used for this research work for data collection. It was made up of different sections, which contained the following; Section A: Sociodemographic data of respondents, Section B: Prevalence of absenteeism among students, Section C: Factors responsible for absenteeism, and Section D: Effects of absenteeism on student's performance.

\subsection{Method of Data Collection}

The questionnaire was distributed to the selected nursing students in their lecture areas and were asked to fill the questionnaire which was collected on same day following its completion.

\section{Result Presentation}

Table 1. Socio-demographic characteristics of respondents $n=270$.

\begin{tabular}{|c|c|c|}
\hline CHARACTERISTICS & FREQUENCY & PERCENTAGE (\%) \\
\hline \multicolumn{3}{|l|}{ SEX: } \\
\hline Male & 87 & 32.2 \\
\hline Female & 183 & 67.8 \\
\hline TOTAL & 270 & 100 \\
\hline \multicolumn{3}{|l|}{ AGE: } \\
\hline$\leq 20$ years & 24 & 8.9 \\
\hline $21-30$ & 198 & 73.3 \\
\hline$\geq 31$ & 48 & 17.8 \\
\hline TOTAL & 270 & 100 \\
\hline \multicolumn{3}{|l|}{ MARITAL Status } \\
\hline Single & 231 & 85.6 \\
\hline Married & 39 & 14.4 \\
\hline TOTAL & 270 & 100 \\
\hline \multicolumn{3}{|l|}{ PRE-ENTRY Qualification: } \\
\hline Sec. Sch. Cert & 207 & 76.7 \\
\hline Registered nurse & 48 & 17.8 \\
\hline Others (BSc./HND/ND ) & 15 & 5.5 \\
\hline TOTAL & 270 & 100 \\
\hline \multicolumn{3}{|l|}{ PLACE OF RECIDENT: } \\
\hline Campus & 189 & 70 \\
\hline $\begin{array}{l}\text { Renting outside campus } \\
\text { Leaving with }\end{array}$ & 48 & 17.8 \\
\hline parent/guardian & 33 & 12.2 \\
\hline TOTAL & 270 & 100 \\
\hline
\end{tabular}


On the socio-demographic characteristics of the respondents, table 1 above showed that, majority of the respondents $(67.8 \%)$ are female while $32.2 \%$ are male. On the age distribution of the respondents, majority of the respondents $(73.3 \%)$ were between the age of $21-30$ years while $17.8 \%$ were 31 and above. Only $8.9 \%$ of the respondents were below 20 years. Majority of the respondents (85.6\%) are single with only $14.4 \%$ married. On the entry qualification, majority of the respondents $(76.7 \%)$ had only secondary certificate, $17.8 \%$ are registered nurses while $5.5 \%$ are having BSc. / HND / ND in other fields of study. Majority of the respondents $(70 \%)$ reside on campus, $17.8 \%$ reside off campus while $12.2 \%$ reside with parents.

Table 2. Prevalence of absenteeism among students.

\begin{tabular}{|c|c|c|c|c|c|c|c|}
\hline $\mathbf{S} / \mathbf{N}$ & ITEMS & SA & $\mathbf{A}$ & D & SD & MEAN & REMARK \\
\hline 1. & Students absent themselves from school & 189 & 57 & 18 & 6 & 3.59 & \\
\hline 2. & Students absent themselves from clinical posting & 136 & 119 & 11 & 4 & 3.47 & \\
\hline 3. & Student attend all classes for a semester & 47 & 51 & 69 & 103 & 2.16 & \\
\hline 4. & Student miss duty during clinical posting & 88 & 97 & 53 & 32 & 2.82 & \\
\hline \multirow[t]{2}{*}{5.} & Student rarely miss classes or clinical posting & 114 & 67 & 65 & 24 & 2.90 & \\
\hline & CLUSTER MEAN & & & & & 2.99 & \\
\hline
\end{tabular}

Note: $<2.50$ means negative, $>2.50$ means positive

From table 2 above, almost all the items in the table have mean scores above 2.50 . The cluster mean of 2.99 shows that there was high prevalence of absenteeism among the nursing students.

Table 3. Factors responsible for absenteeism.

\begin{tabular}{|c|c|c|c|c|c|c|c|}
\hline $\mathbf{S} / \mathbf{N}$ & ITEMS & SA & A & D & SD & MEAN & REMARK \\
\hline 1. & Illness causes students to be absent from classes and clinical posting & 87 & 136 & 39 & 8 & 3.12 & \\
\hline 2. & Long distant cause student to be absent from classes and clinical posting & 98 & 88 & 61 & 23 & 2.97 & \\
\hline 3. & It is nursing mothers that miss classes and clinical posting & 104 & 89 & 63 & 14 & 3.05 & \\
\hline 4. & Lack of transport fare causes students to be absent from clinical posting & 107 & 95 & 59 & 9 & 3.11 & \\
\hline 5. & Lack of interest cause to be absent from classes and clinical posting & 23 & 66 & 84 & 97 & 2.06 & \\
\hline \multirow[t]{2}{*}{6.} & Non-payment of school fees causes absenteeism to classes and clinical posting & 22 & 67 & 85 & 96 & 2.06 & \\
\hline & CLUSTER MEAN & & & & & 2.73 & \\
\hline
\end{tabular}

Note: $<2.50$ means negative, $>2.50$ means positive

From table 3 above, most of the items in the table have mean scores above 2.50 . The cluster mean of 2.73 shows that reasons for absenteeism among the nursing students are multifactorial.

Table 4. Effect of absenteeism on students'academic performance.

\begin{tabular}{|c|c|c|c|c|c|c|c|}
\hline $\mathbf{S} / \mathbf{N}$ & ITEMS & SA & $\mathbf{A}$ & D & SD & MEAN & REMARK \\
\hline 1. & Absenteeism causes student to perform bad in academics & 124 & 111 & 32 & 3 & 3.32 & \\
\hline 2. & Absenteeism does not cause student poor performance & 7 & 11 & 138 & 114 & 1.67 & \\
\hline 3. & Students like poor grade obtained from school & 1 & 3 & 108 & 158 & 1.43 & \\
\hline \multirow[t]{2}{*}{4.} & Students would like to follow best learning method(s) that will help them pass well & 134 & 132 & 3 & 1 & 3.48 & \\
\hline & CLUSTER MEAN & & & & & 2.48 & \\
\hline
\end{tabular}

From table 4 above, the mean score of 3.32 on the first item is a clear indication that absenteeism had a very negative effect on the academic performance of the nursing students.

TESTING OF HYPOTHESES

Hypothesis 1: Nursing students do not miss their lectures

Table 5. Chi-square $\left(X^{2}\right)$ test on prevalence of absenteeism among students.

\begin{tabular}{lllll}
\hline $\mathbf{O}$ & $\mathbf{E}$ & $\mathbf{( E - O )}$ & $(\mathbf{E}-\mathbf{O})^{\mathbf{2}}$ & $(\mathbf{E}-\mathbf{O})^{2} / \mathbf{E}=\mathbf{X}^{2}$ \\
\hline 189 & 114.8 & 74.2 & 5505.64 & 47.96 \\
57 & 78.2 & -21.2 & 449.44 & 5.75 \\
18 & 43.2 & -25.2 & 635.04 & 14.70 \\
6 & 33.8 & -27.8 & 772.84 & 22.80 \\
136 & 114.8 & 21.2 & 449.44 & 3.91 \\
119 & 78.2 & 40.8 & 1664.64 & 21.29 \\
11 & 43.2 & -32.2 & 1036.84 & 24.00 \\
\hline
\end{tabular}




\begin{tabular}{lllll}
\hline $\mathbf{O}$ & $\mathbf{E}$ & $\mathbf{( E - O )}$ & $\mathbf{( E - O )})^{\mathbf{2}}$ & $(\mathbf{E}-\mathbf{O})^{2} / \mathbf{E}=\mathbf{X}^{\mathbf{2}}$ \\
\hline 4 & 33.8 & -29.8 & 888.04 & 26.27 \\
47 & 114.8 & -67.8 & 4596.84 & 40.04 \\
51 & 78.2 & -27.2 & 739.84 & 9.46 \\
69 & 43.2 & 25.8 & 665.64 & 15.41 \\
103 & 33.8 & 69.2 & 4788.64 & 141.68 \\
88 & 114.8 & -26.8 & 718.24 & 6.26 \\
97 & 78.2 & 18.8 & 353.44 & 4.52 \\
53 & 43.2 & 9.8 & 96.04 & 2.22 \\
32 & 33.8 & -1.8 & 3.24 & 0.10 \\
114 & 114.8 & -0.8 & 0.64 & 0.01 \\
67 & 78.2 & -11.2 & 125.44 & 1.60 \\
65 & 43.2 & 21.8 & 475.24 & 11.00 \\
24 & 33.5 & -9.8 & 96.04 & 2.84 \\
Total & & & & 401.89 \\
\hline
\end{tabular}

The calculated $\mathrm{X}^{2}=401.89$

The tabulated $\mathrm{X}^{2}=21.03$

Since the Chi-square $\left(\mathrm{X}^{2}\right)$ test (calculated) $=401.89$ is greater than the tabulated value $=21.03$, there is therefore no statistical evidence to accept the null hypothesis (Ho). This means that nursing students miss lectures.

Hypothesis 2: There are no factors influencing absenteeism among the nursing students

Table 6. Chi-square $\left(X^{2}\right)$ test on factors responsible for absenteeism.

\begin{tabular}{|c|c|c|c|c|}
\hline $\mathbf{O}$ & $\mathbf{E}$ & (E-O) & $(E-O)^{2}$ & $(E-O)^{2} / E=X^{2}$ \\
\hline 87 & 14.5 & 72.5 & 5256.25 & 362.50 \\
\hline 136 & 22.7 & 113.3 & 12836.89 & 565.50 \\
\hline 39 & 6.5 & 29.5 & 870.25 & 133.88 \\
\hline 8 & 1.3 & 6.7 & 44.89 & 34.53 \\
\hline 98 & 14.5 & 83.5 & 6972.25 & 480.84 \\
\hline 88 & 22.7 & 65.3 & 4264.09 & 187.85 \\
\hline 61 & 6.5 & 54.5 & 2970.25 & 456.96 \\
\hline 23 & 1.3 & 21.7 & 470.89 & 362.22 \\
\hline 104 & 14.5 & 89.5 & 8010.25 & 552.43 \\
\hline 89 & 22.7 & 66.3 & 4395.69 & 193.64 \\
\hline 63 & 6.5 & 56.5 & 3192.25 & 491.11 \\
\hline 14 & 1.3 & 12.7 & 161.29 & 124.07 \\
\hline 107 & 14.5 & 92.5 & 8556.25 & 590.09 \\
\hline 95 & 22.0 & 72.3 & 5227.29 & 230.28 \\
\hline 59 & 6.5 & 52.5 & 2756.25 & 424.04 \\
\hline 9 & 1.3 & 7.7 & 59.29 & 45.61 \\
\hline 23 & 14.5 & 8.5 & 72.25 & 4.98 \\
\hline 66 & 22.7 & 43.3 & 1874.89 & 82.59 \\
\hline 84 & 6.5 & 77.5 & 6006.25 & 924.09 \\
\hline 97 & 1.3 & 95.7 & 9158.49 & 7044.99 \\
\hline 22 & 14.5 & 7.5 & 56.25 & 3.88 \\
\hline 67 & 22.7 & 44.3 & 1962.49 & 86.45 \\
\hline 85 & 6.5 & 78.5 & 6162.25 & 948.04 \\
\hline 96 & 1.3 & 94.7 & 8968.09 & 6898.53 \\
\hline Total & & & & 21229.1 \\
\hline
\end{tabular}

The calculated $\mathrm{X}^{2}=21229.1$

The tabulated $\mathrm{X}^{2}=25.00$

Since the Chi-square $\left(\mathrm{X}^{2}\right)$ test (calculated) $=21229.1$ is greater than the tabulated value $=25.00$. There is therefore no statistical evidence to accept the null hypothesis $(\mathrm{Ho})$. This means that there are factors influencing absenteeism among the nursing students.

Hypothesis 3: There are no effects of absenteeism on the students' academic performance

Table 7. Chi-square $\left(X^{2}\right)$ test on effect of absenteeism on student academic performance.

\begin{tabular}{lllll}
\hline $\mathbf{O}$ & $\mathbf{E}$ & $\mathbf{( E - O )}$ & $(\mathbf{E}-\mathbf{O})^{2}$ & $(\mathbf{E}-\mathbf{O})^{2} / \mathbf{E}=\mathbf{X}^{\mathbf{2}}$ \\
\hline 124 & 31.0 & 93.0 & 8649.00 & 279.00 \\
111 & 27.8 & 83.2 & 6922.24 & 249.00 \\
32 & 8.0 & 24.0 & 576.00 & 72.00 \\
3 & 0.8 & 2.2 & 4.84 & 6.05 \\
7 & 31.0 & -24.0 & 576.00 & 18.58 \\
11 & 27.8 & -16.8 & 282.24 & 10.15 \\
138 & 8.0 & 130 & 16900.00 & 2112.50 \\
114 & 0.8 & 113.2 & 12814.24 & 16017.80 \\
1 & 31.0 & -30.0 & 900.00 & 29.03 \\
3 & 27.8 & -24.8 & 615.04 & 22.12 \\
108 & 8.0 & 100 & 10000 & 1250.00 \\
158 & 0.8 & 157.2 & 24711.84 & 30889.80 \\
134 & 31.0 & 103.0 & 10609.00 & 342.23 \\
132 & 27.8 & 104.2 & 10857.84 & 390.56 \\
3 & 8.0 & -5.0 & 25.00 & 3.13 \\
1 & 0.8 & 0.2 & 0.04 & 0.05 \\
Total & & & & 51692.00 \\
\hline
\end{tabular}

The calculated $X^{2}=51692.00$

The tabulated $X^{2}=16.92$

Since the Chi-square $\left(\mathrm{X}^{2}\right)$ test (calculated) $=51692.00$ is greater than the tabulated value $=16.92$. There is therefore no statistical evidence to accept the null hypothesis (Ho). This means that there are effects of absenteeism in the academic performance of the nursing students.

\section{Discussion of Findings}

\subsection{Prevalence of Absenteeism Among Nursing Students}

On the prevalence of absenteeism among students, this study finding revealed high prevalence of absenteeism among the nursing students. The cluster mean of 2.99 as presented in table 1 showed that there was high prevalence of absenteeism among the nursing students. These findings implied that there is a high prevalence of absenteeism to both lectures and clinical postings among nursing students of 
university of Maiduguri Borno state. This finding agrees with that of [12], who conducted a study on prevalence and factors contributed to absenteeism among nursing students at faculty of nursing sciences, university of Khartoum -Sudan with finding which showed prevalence rate of $29.4 \%$. Studies by [13]; [14]; [15]; [16]; [4] lend their support to the findings of this study. Study by [7] also supported the study as their study in Ireland on attitude to absenteeism among diploma nursing students in Ireland revealed absenteeism as a potential problem among nursing student and most of the respondents agree that students attendance at both the practical and theoretical aspect of basic is a problem.

\subsection{Factors Influencing Absenteeism Among Nursing Students}

This study finding revealed that, illness, long distance to school, nursing a baby, lack of interest in lectures and clinical experience, lack of transportation, and non-payment of school fees are contributing factors to absenteeism among nursing students. As shown in table 3, most of the items have mean scores above 2.50. The cluster mean of 2.73 showed that reasons for absenteeism among the nursing students are multifactorial. The findings of this study is supported by [17]; [12] whose studies revealed that contributing factors to absenteeism among students are multifactorial. The findings of this study is further supported by [18] whose study on Causes and structural effects of student absenteeism: a case study of three South African Universities revealed a multifactorial cause. Studies by [19]; [20] also lend their support to the findings of this study.

\subsection{Effects of Absenteeism on the Academic Performance of Students}

This study finding showed that many of the student nurses have experienced academic set-back as a result of absenteeism from either lecture or clinical posting. The types of academic setback experienced include; poor grade, carryover, and repeat of a class. From table 4 above, the mean score of 3.32 on the first item is a clear indication that absenteeism had a very negative effect on the academic performance of the nursing students. Studies by [17]; [11]; [1]; [21]; [22]; [10]; [23] lends strong support to the findings of this research work. [3] also reported absenteeism from teaching area and clinical setting as a potential problem among nursing student.

\section{Implication to Nursing}

The nursing profession is a profession that has a crucial and direct impact in the care of patients. It is important that during the training of students, a strict guideline is to be established and students are to always attained and pay key interest in patient's management. Absenteeism of any kind will lead to having nurses who will not take patient care with seriousness and such nurses will be setbacks to the profession.

\section{Conclusion}

This study is written on absenteeism among nursing students in University of Maiduguri. The study tried to establish the prevalence of absenteeism among students, factors contributing to absenteeism and the effects of absenteeism among the students. This was achieved by the use of questionnaire which was distributed among the students.

The following conclusion can be drowned from the findings of this study;

i. Majority of students do absent themselves from lectures and clinical postings.

ii. Participation in other roles besides academic activities and transportation difficulties are important contributions to absenteeism.

iii. Poor grades and carry-over are effects of absenteeism.

\section{Recommendation}

Based on the above findings, the following recommendations are made.

a) The department of nursing science should endeavor to make clinical experience as interested as possible.

b) Clinical supervision and attendance list should be taken serious during lectures and clinical posting.

c) The school management board should provide free transportation to clinical areas and accommodations should also be provided for students within campus.

d) Lecture halls and theaters should be made as conducive as possible.

\section{References}

[1] Richard C., Sierra F., Forrest M., Sam M., and Travis S (2015) The Effects of Early Chronic Absenteeism on Third-Grade Academic Achievement Measures. Wisconsin Department of Public Instruction, University of Wisconsin-Madison.

[2] Gump, S. E (2006) Guess Who's (Not) Coming to Class: Students Attitude as Indicator of Attendance. Journal of Education Studies, Vol. 32 (1): 39-46.

[3] Timmins F. and Kaliszer M. (2002) Attitudes to Absenteeism Among Diploma Nursing Student in Ireland- An Exploratory Descriptive Survey. Journal of Nurse Education Today, Vol. 22 (7): 578-88.

[4] Balfanz, R., and Byrnes, V. (2012) The Importance of Being in School: A Report on absenteeism in the Nation's Public Schools. Baltimore: Johns Hopkins University Center for Social Organization of Schools.

[5] Hughes S. L (2005) Students attendance During College Based Lectures: A Pilot Study. Journal of Nursing Standard, Vol. 19 (47); 41-49.

[6] Leonard C., Bourke S. and Schofield N (2000) Quality of School Life and Absenteeism in Primary Schools. Paper Presentation at the Annual Conference of the Australian Association of Research in Education, Sydney. 
[7] Timmins F. and Kaliszer M. (2002). Absenteeism among students - fact or fiction? Journal of Nursing Management, Vol. 10 (5): 251-264.

[8] Castledine, C. (2000) The Failure of Nursing Students to Attend Classes. British Journal of Nursing, Vol. 9 (20): 2127.

[9] Longhurst R (1999) Why Aren't They Here? Student Absenteeism in a Further Educational College. Journal of further and Higher Education, Vol. 23 (1): 61-80.

[10] Gottfried, M. A. (2010). "Evaluating the Relationship Between Student Attendance and Achievement in Urban Elementary and Middle Schools An Instrumental Variables Approach." American Educational Research Journal 47 (2): 434-465.

[11] Genao, S. (2015). "Utilizing Data to Combat Absenteeism and Decrease Dropout Rates". Education and Urban Society. 47 (4): 463-475.

[12] Faiza A. N (2015) Prevalence and Factors Contributed to Absenteeism among Nursing Students at Faculty of Nursing Sciences, University of Khartoum -Sudan. International Journal of Medical and Health Sciences, Vol. 4 (4) Pp. 408-413.

[13] Gottfried, M. A. (2014). "Can Neighbor Attributes Predict School Absences?" Urban Education 49 (2): 216-250.

[14] Anteneh A. D., Asres B. and Yifru B (2014) Absenteeism Among Medical and Health Science Undergraduate Students at Hawassa University, Ethiopia. Journal List BMC Med Educ Vol. 14: 81 doi: 10.1186/1472-6920-14-81

[15] Kelly K. S (2013) Chronic Student Absenteeism: Implications for School Leaders. Dissertation for Doctor of Education in Educational Organization and Leadership in the Graduate College of the University of Illinois at Urbana-Champaign.
[16] Balfanz, R. and Vaughan B. (2012). "The Importance of Being There: A Report on Absenteeism in the Nation's Public Schools." Baltimore, MD: Johns Hopkins University School of Education, Everyone Graduates Center, Get Schooled: 146.

[17] Demir, K. and Akman Karabeyoglu, Y. (2015). Factors associated with absenteeism in high schools. Eurasian Journal of Educational Research, 62, 37-56 http://dx.doi.org/10.14689/ejer.2016.62.4.

[18] Wadesango N, Machingambi S. (2011) Causes and Structural Effects of Student Absenteeism: A Case Study of Three South African Universities. J Soc Sci Vol. 26 (2): 8 9-97.

[19] Kearney, C. A. (2008). An interdisciplinary model of school absenteeism in youth to inform professional practice and public policy. Educational Psychology Review, 20, 257-282.

[20] Pellegrini, D. W. (2007). School non-attendance: Definitions, meanings, responses, interventions. Educational Psychology in Practice, 23 (1), 63-77.

[21] Ahmed A. A., Zeynab A. Y., and Ahmed M. D (2013) The Effects of Student's Attendance on Academic Performance: A Case Study at Simad University Mogadishu. Journal of Academic Research International, Vol. 4 (6) pp. 409-417.

[22] Ümit Ö and Nadire A (2011) The Relation between Success and Absenteeism at Esogu English Preparatory School. Journal of Language Teaching and Research. 2011 Jan; 2 (1): 68-72. ISSN 1798-4769.

[23] Balfanz, R., Liza H., and Douglas J. M (2007). "Preventing Student Disengagement and Keeping Students on the Graduation Path in Urban Middle-grades Schools: Early Identification and Effective Interventions." Educational Psychologist 42 (4): 223-235. 